\title{
A violência como objeto da assistência em um hospital de trauma: "o olhar" da enfermagem
}

\author{
Violence as object of care in a trauma intensive \\ care unit: the nurses' "view"
}

Sandra M aria Cezar Leal 1

M arta Júlia M arques Lopes 2

${ }^{1}$ Curso de Enfermagem da Unisinos.

Rua Dr. Mário Totta 1.257/405, 91920-130, Porto Alegre RS. sandral@cpovo.net 2 Escola de Enfermagem, UFRGS.
Abstract This study is based on hybrid typology. The objective is to know and understand the "perspective" and responses of the nurses when caring for a patient that was the victim of violence and hospitalized with services in a trauma intensive care unit. The study was carried out in Porto Alegre, in a public hospital in the emergency trauma center. The subjects are professionals of the nursing team from intensive care units and the patients hospitalized were victims of violence in 2001. The quantitative data came from the hospitalization records and were analyzed with absolute and relative frequency rates with help from Epi-Info software. The Thematic Content Analysis was adopted for discursive data. Of 697 patients hospitalized in this period, victims of violence, $90.5 \%$ were males; $73 \%$ were whites and $27 \%$ were blacks or of black descent; the age bracket of 11 to 39 years old corresponded to $78.9 \%$ of the hospitalizations; $47.9 \%$ were injured with a handgun, $26.5 \%$ by a knife or cutting edge, $25 \%$ by physical aggression, and $0.3 \%$ were victims of rape. In relation to the nursing "perspective" as to patient care, the concern of the workers and the difficulties they face became evident. It is pointed out that public health services need to analyze this and create spaces of co-responsibility in this process.

Key words Violence and trauma, Care, N ursing, Emergency, H ospitalization
Resumo A pesquisa apóia-se na tipologia dos estudos híbridos. 0 objetivo é conhecer e compreender o "olhar" e o fazer das trabal hadoras de enfermagem no cuidado ao paciente vítima de violência, hospitalizado em serviços de emergência em trauma. Foi realizada em um hospital público de emergência em trauma, em Porto Alegre. Os sujeitos são os profissionais da equipe de enfermagem das unidades de internação e os pacientes internados vítimas de violência, em 2001. Os dados quantitativos são originários dos registros de internação do hospital e foram analisados com índices freqüenciais absolutos e relativos, com auxílio do software Epi-Info; para os dados discursivos adotou-se a Análise de Conteúdo. Dos 697 pacientes hospitalizados, vítimas de violência, $90,5 \%$ eram do sexo masculino; $73 \%$ brancos e $27 \%$ negros ou descendentes dessa etnia; a faixa etária dos 11 aos 39 anos corresponde a 78,9\% das internações; $47,9 \%$ agredidos por arma de fogo, 26,5\% por arma branca, $25 \%$ por agressão física, 0,3\% vítimas de estupro. Em relação ao "olhar" da enfermagem no cuidado ao paciente ficou evidente a preocupação das trabalhadoras e as dificuldades desse enfrentamento. A ponta-se, que os serviços públicos de saúde necessitam se auto-avaliar e propiciar a criação de espaços de co-responsabilização nesse processo.

Palavras-chave Violência e trauma, Cuidado, Enfermagem, H ospitalização, Emergência 


\section{Introdução ao problema investigado}

Este artigo é originário da dissertação de mestrado de Leal (2003) e integra o Núcleo de Estudos Interdisciplinares de Gênero, Saúde e Trabal ho da Escola de Enfermagem da Universidade Federal do Rio Grande do Sul. Aborda a violência como objeto da assistência, a partir de indivíduos internados em um hospital de pronto-socorro em trauma de Porto Alegre, e discute a ação dos profissionais de saúde envolvidos nesse cuidado.

O tema violência e saúde começou a ser pesquisado, no Brasil, na década de 1980 , denunciando o impacto da violência na saúde da população brasileira (Barros, 1984; Zaluar, 1986, entre outros). A violência é um fenômeno social que atinge populações, no espaço público e privado (Abramovay et al., 2002), atualmente está presente no cotidiano das grandes cidades e representa uma ameaça à população, porém, alguns grupos sociais e étnicos estão mais vulneráveis. M inayo et al. (1999) consideram que não há um fato denominado violência, e sim violências, manifestações da exacerbação de conflitos sociais cujas especificidades precisam ser conhecidas, e que têm profundos enraizamentos nas estruturas sociais, políticas, econômicas e nas consciências individuais.

Deslandes (1999) amplia a denominação da morbidade por causas externas (homicídios, suicídios, acidentes), pois considera difícil discernir a especificidade que envolve cada um dos fenômenos causadores da violência, e pergunta: "causas externas por que sempre foram um problema social e não da área da saúde?" Seguindo essa idéia, é possível afirmar que o profissional de saúde está pouco atento para identificar as várias faces dos atendimentos incluídos na classificação de causas externas, pois é comum, na emergência, desconsiderar a violência causa, e quando identificada considerála um evento normal para o tipo de pessoa que está sendo atendida ou fazer o registro incompleto. No Brasil, as causas externas são o principal motivo de morte nos grupos etários de 5 a 45 anos (M inayo \& Souza, 1993; Chesnais, 1999). M inayo \& Souza (1999) afirmam que a incidência das mortes violentas recai sobre a população masculina de adolescentes e adultos jovens oriundos das classes sociais menos favorecidas, de etnia negra ou dela descendentes, com pouca ou nenhuma qualificação profissional e com baixa escolaridade. Sant'Anna (2000) retrata essa realidade, a partir de um estudo só- cio-histórico das mortes violentas dos adolescentes na cidade de Porto Alegre, em 1997, corroborado por Lopes et al. (2002).

Para Sant'Anna os serviços de emergência estão voltados para a queixa do momento, e a crescente demanda dificulta a oferta de um atendimento articulado e conseqüente (2000). D eslandes (2002) enfatiza que os profissionais de saúde convivem diariamente com a violência na demanda dos atendimentos e ressalta a importância desses serviços na avaliação da repercussão da violência na saúde. Concordamos com essas autoras, pois, em hospitais de atendimento ao trauma as relações de trabal ho dos profissionais de saúde ocorrem na emergência e em unidades de internação superlotadas, e é neste contexto que estão inseridos os objetivos desta pesquisa. Partimos do pressuposto que os que sobrevivem à violência buscam as emergências públicas $\mathrm{e}$ que os profissionais de saúde não estão preparados para se envolverem com essas vítimas senão com 0 atendimento ao trauma. 0 serviço de notificação é precário ou inexistente, de modo que a violência não é "diagnosticada", ou o fato étratado como "lesão causada por agressão" e, em algumas situações, o plantão policial faz o registro de ocorrência. Conforme D eslandes:

[...] em nenhum outro serviço de saúde a violência adquire tamanha visibilidade como na emergência. [...] é, para a maioria das vítimas de violência, a "porta de entrada" no sistema público de saúde. [...] Para muitas pessoas é a única vez em que estará, enquanto vítima de uma agressão, diante de um profissional de saúde (que é um representante do poder público). Em muitos casos é um dos únicos momentos em que a violência será declarada (D eslandes, 1999).

A pesar de concordar com essa afirmativa, consideramos prioritário o preparo dos profissionais da saúde para essa função. Em geral, saem das universidades sem condições de assumir a responsabilidade de trabalhar em um serviço público "em defesa da vida" dos usuários, ou com capacidade para "escutar" o que o paciente diz e o que não diz e "ver" o que está por trás de uma "queda" ou de um "assalto". As condições psicológicas para suportar esse "olhar" sobre a violência merecem ser consideradas na qualificação do profissional de saúde, pois sua atuação assume outra dimensão quando compreende a trama das relações sociais conflituosas que se originam nas ruas e chegam aos serviços de emergência (Skaba, 1997).

Por outro lado, a superlotação dos hospitais públicos, as filas intermináveis de usuários nas 
emergências, para resolver o que a atenção básica e os postos da saúde não dão conta, associados ao sentimento de impotência e à reprodução acrítica dos valores social mente aceitos causam, aos profissionais de saúde, sofrimento e contribuem para que alguns desenvolvam um processo de naturalização destas condi ções (Skaba, 1997).

0 atendimento ao usuário em um hospital de emergência é voltado à lesão causada pelo trauma e não inclui um "olhar" à violência, pois esta não é considerada um problema de saúde, e em muitos atendimentos não éidentificada como causa do trauma.

A realidade do cuidado, em um hospital de emergência em trauma, só é vivida e explicada por quem faz parte desse cotidiano (o profissional de saúde), pois, para ele, não existe emergência lotada, horário ou limite para as internações. Em finais de semana e feriados, a equipe não é reduzida, como é rotina nos demais hospitais. A equipe de enfermagem deve manter o mesmo contingente de trabal hadores e, não raro, trabalhar em horário extra, pois, nesses períodos, aumentam os atendimentos e hospitalizações, porque nem todos os hospitais do interior do Estado têm plantão de atendimento em emergência. $\mathrm{O}$ H ospital de ProntoSocorro em estudo é, portanto, um serviço com ritmo constante nas 24 horas do dia, sete dias por semana.

Nesta pesquisa os profissionais de saúde são representados pelas trabalhadoras de enfermagem, que como os demais convivem, no mesmo espaço, tanto com a vítima de agressão, quanto com 0 agressor - também agredido. É comum, no corredor do hospital, transitarem indivíduos al gemados e policiais munidos de armamentos pesados - metral hadoras, fuzis. Faz parte do trabalho cotidiano do hospital cuidar de pacientes custodiados - acorrentados ao leito - vigiados por agente policial.

N esse contexto, as trabalhadoras de enfermagem constroem "seu ol har" no cuidado ao paciente hospitalizado em decorrência da violência. Quanto ao processo e relações de trabaIho, vários autores referem-se a estratégias dos trabalhadores para suportarem o sofrimento causado pela natureza, organização e pelas condições de trabalho (Bouvier, 1989; D ejours, 1988; Pitta, 1991; Tittoni, 1994; Lopes, 1995, entre outros).

Este artigo aborda esse tema equestiona: De que modo a enfermagem olha a violência como objeto da assistência em um hospital de trauma? As trabalhadoras de enfermagem estão atentas para identificar as várias faces do atendimento ao usuário em situação de violência? Consideram essa identificação necessária ao seu desempenho profissional? Qual o papel que desempenham como representantes do poder público, no cuidado aos usuários em um serviço público de emergência? 0 paciente vítima de violência é diferente dos demais? Quais são essas diferenças? Interferem no cuidado? Deque modo?

Para responder a esses questionamentos é necessário entender o contexto das internações decorrentes de violência; conhecer e compreender o "olhar" e o fazer das trabal hadoras de enfermagem no cuidado ao paciente vítima de violência, hospitalizado em serviços de emergência em trauma.

\section{Metodologia}

0 estudo desenvolvido é de desenho exploratório e analítico, apóia-se na tipologia dos estudos híbridos, associando quantificações e dados qualitativos.

A pesquisa foi realizada em um hospital público de emergência em trauma, na cidade de Porto Alegre (RS). Os sujeitos são os profissionais da equipe de enfermagem das unidades de internação e os pacientes caracterizados são os internados vítimas de violência, no ano de 2001.

Os dados qualitativos foram coletados mediante a técnica de entrevista semi-estruturada, entrevistando-se representantes de todas as categorias de profissionais da enfermagem (uma enfermeira e uma auxiliar ou técnica de cada unidade de internação). Os dados para caracterização dos pacientes, quanto sexo, idade, raça/cor, mês da internação e endereço de al guns pacientes são provenientes dos registros de internação do hospital, que são processados pela Companhia Rio-Grandense de Processamento de Dados do M unicípio de Porto Alegre (PROCEM PA - órgão da Prefeitura M unicipal de Porto Alegre, que faz o processamento dos dados do HPS).

No período estudado (janeiro a junho de 2001), 715 pessoas foram hospitalizadas por "causas" relacionadas à violência e agrupados pela classificação "causas da internação". Os 715 prontuários foram pesquisados no Serviço de D ocumentação e Estatística (SDE) do H PS, para identificar os endereços incompletos ou 
inexistentes e o diagnóstico. Excluindo-se os prontuários que não evidenciavam violência, obteve-se o total de 697 sujeitos.

0 tratamento dos dados quantitativos foi realizado com auxílio do software Epi-Info, e analisados através de índices freqüenciais absolutos. Para a análise dos dados discursivos adotou-se a Análise de Conteúdo do Tipo Temático (M inayo, 2000), privilegiando-se as seguintes categorias temáticas: as trabalhadoras de enfermagem e a violência como problema social; quem são os pacientes no olhar das trabaIhadoras de enfermagem; 0 enfrentamento cotidiano com a violência nas relações e processos de trabal ho; estratégias de enfrentamento no cuidado às vítimas e agressores.

A autorização para a utilização dos dados foi obtida na aprovação do projeto de pesquisa, pelo Comitê de Ética e Pesquisa do H ospital de Pronto Socorro de Porto Alegre. Após, os sujeitos do estudo foram convidados a participar da pesquisa, mediante entrevistas e assinatura do Termo de Consentimento Livre e Informado, baseado na Resolução no 196, de 10 de outubro de 1996, do Conselho Nacional de Saúde (Brasil, 1996).

\section{Alguns resultados}

\section{Paciente vítima de violência e sua hospitalização no H PS}

Foram identificadas 697 internações, que evidenciavam a violência como causa e iniciou-se o resgate da identificação dos sujeitos, pela descrição dos pacientes quanto ao sexo, à faixa etária, à raça/cor, ao tipo de violência, ao local de origem dos pacientes, a fim de construir as informações que possi bilitam evidenciar as vulnerabilidades a que esses indivíduos estão expostos.

A prevalência do sexo masculino (90,5\%) em relação ao feminino $(9,5 \%)$ corroborou com outras pesquisas sobre o tema (Souza \& M inayo, 1999; Sant' Anna, 2000), além da predominância da faixa etária entre 20 e 29 $(41,0 \%)$, seguida das faixas etárias entre 11 e 19 anos e 30 e 39 anos, com, respectivamente, $19,5 \%$ e $18,4 \%$ das internações por violência. A faixa dos 11 aos 39 anos corresponde a $78,9 \%$ das internações, confirmando dados de M inayo et al. (1999), M inayo \& Souza (1999), Sant'Anna (2000), Lopes et al. (2002) eWesthal (2002).
Quanto à raça/cor dos indivíduos em estudo, $73 \%$ são brancos; $12,9 \%$, pardos e $14,1 \%$, negros, num primeiro momento os dados mostram que a população branca está mais exposta à violência. Entretanto, ao comparar a proporção entre as internações por violência quanto à raça/cor e a população de Porto Alegre (IBGE, 2002), as internações são mais freqüentes nos indivíduos negros ou descendentes desta etnia, correspondendo respectivamente a $0,17 \%$ e $0,5 \%$ da população de Porto Alegre. Nunes (2002), ao refletir sobre as desigualdades raça/cor, afirma que basta que olhemos para os lados, entremos nos postos de saúde do SUS, nas escolas de periferia mais depreciadas, nos bairros e favelas mais distantes, e encontraremos como maioria os rostos dos afro-descendentes, aquel es e aquel as a quem a cidadania e os direitos humanos ainda constituem um desejo a ser realizado.

Os tipos de violência foram classificados conforme o registro da causa da internação. D os 697 hospitalizados, 47,9\% foram agredidos por arma de fogo (AAF), 26,5\%, por arma branca (AAB), $25 \%$ são vitimas de agressão física e $0,3 \%$, de estupro. As AAF estão relacionadas a assaltos, envolvimento com a polícia, desavenças entre gangues e crimes passionais. As AAB estão relacionadas a desavenças familiares, briga em bares, envolvendo o consumo deálcool.

Há o registro de dois casos de estupro e envolve crianças; não há registro envolvendo muIheres adultas. Entretanto, na pesquisa dos prontuários identificou-se a internação de uma mulher com trauma de face, que informou ter sido vítima de assalto e, após al guns dias, contou à equipe de psicologia que tinha sido víti ma de estupro.

Quanto aos diagnósticos, relacioná-los ao tipo de violência permite evidenciar o tipo de cuidado que a equipe de enfermagem necessita prestar a esses pacientes. Os mais freqüentes são o trauma abdominal, trauma torácico, traumatismos múltiplos, traumatismo craniencefálico (TCE).

É possível afirmar que a violência contra a mulher é diferente da violência infligida ao homem, pois para as mulheres as internações ocorrem mais precocemente, a faixa etária de 10 a 19 anos representa $25,7 \%$. A mesma faixa etária para os homens representa $17,3 \%$ das internações. 0 trauma torácico e os traumatismos múltiplos são os diagnósticos mais freqüentes para as mulheres, seguidos dos trau- 
matismos craniencefálicos e traumas de face associados ou não ao TCE, o que evidencia que essas mulheres, mesmo em número menor do que o dos homens, são vítimas de traumas graves e com risco de vida. Entretanto, $100 \%$ das mortes no primeiro atendimento são de homens, a maioria entre 10 e 39 anos.

A maioria dos pacientes $(59,54 \%)$ procede de Porto Alegre e de 16 bairros, os mais freqüentes são: Partenon, Restinga, Lomba do Pinheiro e Cristal. Os indivíduos sem residência fixa ou moradores de rua representam 2,9\% dos pacientes procedentes de Porto Alegre, hospitalizados no HPS, no período em estudo. Conforme a procedência informada nos prontuários, os pacientes hospitalizados por violência provêm das regiões da cidade menos favorecidas econômica e socialmente.

Esses dados permitiram territorializar a origem da população em estudo e referenciar os possíveis focos de violência na cidade de Porto Alegre, região metropolitana e interior do Estado.

\section{Trabalhadoras de enfermagem no contexto de um hospital público de atendimento ao trauma}

0 depoimento que segue ilustra a rotina de uma unidade de internação de um hospital de emergência em trauma.

[...] gente, médico entrando e saindo, enfermeira [...] paciente, em choque, parando [...] aí tu tá atendendo um paciente vem chegando a tua baixa tens que largar aquele teu paciente para atender a baixa, ele já não aceita a interrupção do cuidado, 0 outro lá também não aceita esperar, o teu colega também precisa sair para fazer uma outra atividade, [...] é uma alta rotatividade dentro de uma unidade. (Auxiliar de Enfermagem)

Nesse contexto, aborda-se o cotidiano de trabal ho da enfermagem, partindo das seguintes categorias: Trabal hadoras de enfermagem e a violência como problema social; Quem são os pacientes sob o olhar da enfermagem; 0 enfrentamento cotidiano da violência nas relações e processos de trabal ho da enfermagem; Estratégias de enfrentamento no cuidado às vítimas e agressores.

$\mathrm{Na}$ categoria "Trabal hadoras de enfermagem ea violência como problema social" estão agrupadas as reflexões das trabal hadoras sobre como vêem a violência, em especial as agressões físicas, e com o quê mais se preocupam.
Eu me preocupo com o avanço das armas de fogo [...].Vai ser cada vez pior? [...] para essa mudança acontecer, vai ter que ser em nível político, socioeconômico, no modelo econômico. (Enfermeira)

A vida para eles não vale nada, se tiverem que te dar um tiro para pegar o teu relógio, eles vão dar [...]. (Auxiliar de Enfermagem)

$\mathrm{N}$ a sociedade e, conseqüentemente, no imaginário social, fortalece a crença de que cada um é responsável por si, e que todos têm as mesmas oportunidades de serem trabal hadores ou marginais. D essa forma, fica evidente que, se "alguns" escolhem o "caminho do mal" nada se pode fazer para mudar o rumo dessa história. Assim, o mundo fica dividido entre os que trabalham e conseguem adquirir dignamente os bens de consumo e os que fazem a opção de adquirir os mesmos bens através de meios "mais fáceis" (ou possíveis?) como o narcotráfico, assaltos, roubos seqüestros, homicídios.

Algumas trabalhadoras correlacionam violência com desigualdades sociais e violência com pobreza e desemprego. Briceño-León (2002) ressalta que a violência pode ser gerada pela associação da pobreza com a desigual dade social, por exemplo, o Brasil, onde os maiores índices de violência não são registrados nos Estados pobres do N ordeste, mas naqueles onde se concentra o maior poder aquisitivo e as desigualdades sociais - Rio de J aneiro e São Paulo.

A categoria " $Q$ uem são os pacientes sob o olhar das trabalhadoras" trata dos que são internados em decorrência de violência e são "diferentes" dos demais. Cuidar de um indivíduo que sofreu acidente de trânsito é diferente de cuidar daquele que se interna por agressão. Essa diferença não é sinalizada de imediato. A maioria considera que 0 atendimento éigual para todos, e em nenhum momento deixam de prestar a assistência necessária e prescrita que resumem em "higiene e conforto, aplicação de medicações, curativos, entre outros". Porém, à medida que começam a refletir sobre o que sentem, pensam e fazem para lidar com esses pacientes, começam a expressar essas diferenças, afirmando que esses pacientes: são agressivos, pouco esclarecidos, com pouco estudo, mais homens. Internam por arma de fogo e arma branca, dizem que foram agredidos e não sabem porque, estão envolvidos com crime e em geral são marginais. [...] querem mandar na gente, é difícil com eles [...]. (Auxiliar de Enfermagem)

O sentimento de vingança expresso pela vítima de violência, em especial os que conhecem 
o agressor, é visto como característica desses pacientes. A dor do trauma físico se mistura ao sentimento de derrota e, no período em que estão no hospital, planejam "ajustar as contas", ou seja, dar continuidade ao ciclo de violência.

Eles não são passivos e ao mesmo tempo em que não referem dor, ficam tentando revidar 0 que aconteceu [...] vingança [...] predominam jovens, ferimentos por arma de fogo e branca, agressões físicas, predomina o sexo masculino. (Enfermeira)

Essa é uma das situações em que os profissionais de saúde devem estar capacitados para enfrentar, de modo interdisciplinar einterinstitucional, para ter meios de cuidar e tratar além do trauma físico. Entretanto, essa perspectiva ainda não existe no serviço público de saúde, e esses pacientes, muitas vezes, recebem o "rótulo" de merecedores do trauma, pois o evento não foi acidental. M uitas vezes, prevalece $a$ atitude julgadora e a terapêutica transforma-se em punição (Lopes, 1995).

Eles procuram isso para estarem aqui, se fosse só acidente, infarto, daria bem menos trabalho e menos gastos [...] não precisaria ter ninguém internado por facada [...]. (Auxiliar de Enfermagem)

As trabal hadoras também se referem à naturalidade com que os pacientes comentam o que Ihes aconteceu, como foi a agressão e a habilidade em conseguir permanecerem vivos.

Ele conta com normalidade sem tamanho, conta as proezas: "levei tantos tiros", é um troféu para eles, "eu tenho tantos no meu corpo" [...]. (Auxiliar de Enfermagem)

A arma de fogo, principalmente entre os jovens, tem função simbólica importante: representa masculinidade, capacidade de se defender e demonstrar coragem. Essa construção simbólica prende-se à construção cultural da masculinidade e está relacionada ao rol de ousadia e valentia. Já, evitar o conflito é um sinal de feminilidade (Briceño-León, 2002). Sobreviver à violência provocada por arma de fogo ou arma branca pode ser considerado "um troféu", pois o indivíduo é "homem suficiente para correr o risco" e sobrevive. Sua masculinidade é reforçada e estará pronto para outro enfrentamento, pois muitos acreditam que não "nasceram pra semente" (Oliveira, 2001). A autora afirma que a expressão "eu não nasci pra semente" era repetida pelos adolescentes da $\mathrm{Fe}$ bem quando Ihes perguntava o que queriam fazer e se queriam sair dali, e que o significado dessa frase é: "eu posso morrer [...] não sou planta que vai vigorar [...]". Considera ainda que a violência está também plantada no corpo deles, como se não pudessem sustentar mais nenhuma vida (Oliveira, 2001).

As trabal hadoras revelam a dificuldade de considerar o paciente "trabalhador" da mesma forma que o "marginal", pois ambos ocupam locais diferentes na sociedade e representam "o bem e o mal": "o cidadão de bem", agredido num assalto, e o "bandido", agredido ao tentar fugir da polícia, estão lado a lado na enfermaria, os cuidados são os mesmos e, às vezes, 0 "bandido" está em piores condições clínicas. Considera-se que o conflito vivido pela equipe de enfermagem nesse convívio dual ista com o "cidadão de bem" e com "o bandido" pode ser minimizado ao se inserir a discussão sobre exclusão e vulnerabilidade.

Outra situação de conflito é o cuidado ao paciente custodiado.

Dos últimos que tenho mais lembrança [ ...] eles têm um perfil de presidiário, de custodiado, eles já tem um perfil de crime, dejá ter praticado crime. (Enfermeira)

0 paciente custodiado é o indivíduo que sofre trauma em decorrência de violência em assaltos, confronto com a polícia ou com membros de grupos criminosos e é preso. Entretanto, a gravidade do trauma não permite que vá para o presídio. Esse paciente é hospitalizado na enfermaria, conforme o diagnóstico, junto com os demais pacientes e fica acorrentado ao leito com um policial civil fazendo a escolta. Durante o período do atendimento ambulatorial, o paciente transita pelo hospital com uma escolta policial fortemente armada e, na medida do possível, é atendido antes dos demais cidadãos, para não expor os usuários ao risco de violência envolvendo policiais ecustodiado. No decorrer da hospitalização, é comum um agente ficar de "sobreaviso" por estar acompanhando mais de um paciente custodiado, em enfermarias diferentes. Essas situações causam insegurança em muitas trabalhadoras, e concordamos com Deslandes (2002) ao considerar que esse é um processo que exige um aprendizado fundamental para esses profissionais.

Q uanto ao sexo, constata-se que homens e mulheres são agredidos em espaços sociais diferentes. 0 espaço doméstico é, de certa forma, isento de leis formais. A banalização do ditado "em briga de marido e mulher ninguém mete a colher" abre caminhos para a "lei do mais forte", legitima o poder do marido sobre a esposa e os filhos e o estabel ecimento de uma "ética 
privada" que hierarquiza as relações familiares, que parece descompromissada com outros valores da sociedade.

Em geral, as mulheres são agredidas no espaço doméstico (Angulo-Tuesta, 1997; Sant' Anna, 2000; Deslandes, 2002). Entretanto, nesta pesquisa a maioria das mulheres está sem 0 registro do endereço, que só foi encontrado nos prontuários, o que provoca questionamentos sobre onde essas mulheres são agredidas; se têm residência fixa; e se chegam sozinhas no HPS, sem condições de informar o en dereço pela gravidade do trauma? 0 dado não é registrado por não ser considerado importante diante da queixa clássica de assal to? É preciso refletir.

A agressão contra a mulher é um desafio para os profissionais de saúde. Constata-se que ainda existe a crença que a deci são de viver ou morrer é da mulher e deve ser respeitada, faz parte do "seu destino".

Ela tem uma cicatriz no rosto e ficou com a boca torta, o marido que causou o corte [...] já esteve aqui por agressão e tinha sido agredida pela mesma pessoa, só que agora ela já estava separada "parece um carma". (Auxiliar de Enfermagem)

Dagord (2002) ressal ta que esse tipo de violência tende a se tornar natural pelo senso comum, e que essa realidade só será modificada com o entendimento e a alteração das circunstâncias que tornam a violência masculina contra as mulheres um padrão comum, que continua a se reproduzir sob o ol har indiferente de grande parte da sociedade. Já, Sant'Anna e Lopes (2002) em um estudo sobre homicídios em adolescentes, relatam que, para a maioria das adolescentes assassinadas, o responsável pelo homicídio foi o companheiro e o principal motivo foi o ciúme, estabelecendo nexo do poder masculino sobre o corpo feminino.

Pesquisadoras e militantes feministas (Angulo-Tuesta, 1997; M inayo \& Souza, 1999; Deslandes, 2002; N egrão, 2002; entre outras) enfatizam a necessidade de o poder público assumir essa situação como um problema de saúde pública e, principalmente, capacitar os profissionais de saúde para o exercício dessa função. O s hospitais de emergência em trauma necessitam de um serviço que possa ser acionado imediatamente diante da suspeita de agressão doméstica, para que o profissional de saúde tenha claro o seu papel e a sua obrigação de intervir, não só como um cidadão sensibilizado, mas como representante do Poder Público. As iniciativas individuais, além de não serem resolutivas, reforçam a construção de que as muIheres se submetem à vergonha e à humilhação de serem agredidas por seus companheiros, por escolha pessoal.

Já vi muitos casos que foram a óbito, chegaram com história de tentativa de suicídio, mas, foram agredidas [...] 0 queimado, dependendo da situação acaba evoluindo para óbito, é uma coisa complicada porque essa situação fica impune; [...] um mês após [...] quando ela ou ele morre [...] isso não é considerado e é comum acontecer [...] só percebi, quando comecei a me perguntar quem está respondendo por isso e descobri que nada é registrado, não é feita nenhuma ocorrência policial, nada [...]. (Enfermeiro)

[...] a gente fica sabendo da história com 0 paciente, porque geralmente ele chega lúcido e nunca imagina que vai morrer, chega falando contigo, contando o que aconteceu e tu tens o privilégio (infelizmente) de ter um interlóquio com ele, até bem íntimo, porque tu ficas sozinho e se tu tens técnica para entrevistar el eacaba contando. (Enfermeiro)

Nesta fala o enfermeiro ressal ta o espaço que o profissional de saúde ocupa, o seu envolvimento nas situações relacionadas às internações decorrentes da violência, e a necessidade de desenvolver um modo de "olhar" que identifique o que está por trás de uma tentativa de suicídio ou de trauma acidental. Assim, a "técnica de entrevista" é instrumento importante para identificar a violência. Os serviços poderiam evitar que os profissionais de saúde vivessem o constrangimento de serem coniventes com graves situações em que óbitos por tentativas de homicídio sejam considerados decorrências de traumas acidentais ou tentativa de suicídio.

Atualmente, no H PS, existe uma sensibilização dos profissionais de saúde, em especial os da enfermagem, para detectar casos de violência contra as mulheres ali hospitalizadas e, quando identificados, são encaminhados à equipe de psicologia que os acompanham durante a hospitalização. N os casos mais graves, 0 serviço social é acionado e é feita a tentativa de encaminhar essa mulher para a Casa Abrigo (Casa de Apoio Viva M aria, em Porto Alegre, que abriga e acolhe mulheres em situação de violência. 0 trabalho é feito por uma equipe multidisciplinar). No entanto, a notificação ainda é precária e muitas mulheres agredidas pelos companheiros têm alta do hospital sem serem identificadas como tal ou, quando identificadas 
e encaminhadas, ainda permanecem nos registros sob a classificação de "agressões outras".

As crianças internadas em decorrência de violência doméstica encontram um envolvimento diferenciado, pois, institucionalmente, existem mecanismos para acompanhá-las e encaminhá-las ao tratamento não só do trauma, mas quanto à sua proteção contra maus-tratos. Em al gumas situações, a internação da criança não é indicada pela gravidade do trauma, mas para esclarecer se o trauma é decorrente de violência doméstica.

O ol har dos profissionais de saúde na detecção dos casos de violência à criança é um exemplo do envolvimento do poder público com políticas que instrumentalizam o profissional para o encaminhamento dos casos aos órgãos competentes: para o Comitê de Proteção à Criança e ao Adolescente do HPS, constituído por uma equipe multiprofissional e, quando necessário, o Conselho Tutelar é acionado.

A possibilidade de detectar maus-tratos à criança e poder acompanhar o encaminhamento do caso diminui o sentimento de impotência, sensibiliza e mobiliza as trabal hadoras para desenvolver um olhar voltado para a identificação e o encaminhamento dessas situações. Entretanto, a violência à criança, em especial o abuso sexual, causa sentimento de indignação e revolta na equipe de enfermagem. Além da brutalidade da agressão, envolve a família que deveria ser o local de segurança para todas as crianças e, segundo Oliveira (2002), os profissionais de saúde, em especial os que estão nos serviços públicos, devem estar preparados para essa realidade crua e cruel que atinge as nossas crianças e adolescentes no Brasil.

A categoria "Enfrentamento cotidiano com a violência nas relações e processos de trabalho da enfermagem" resultou do questionamento às trabalhadoras sobre a violência - da cidade, da vida urbana - e sua interferência, na rotina do cuidado aos pacientes hospitalizados, no HPS. N as suas falas, a violência interfere tanto no seu trabalho quanto na sua vida privada, pois convivem com o risco de uma eventual agressão no próprio local de trabalho, ou seja, "quando" a violência fica próxima e a segurança do ambiente de trabalho é ameaçada.

Entretanto, al gumas trabal hadoras relatam que já aprenderam a lidar com essas situações. Em relação à interferência no cuidado e às dificuldades, afirmam:

A tualmente, o maior número de internações tem sido por agressões, eu acredito que $70 \%$ das internações [ ...]. Então a gente se habitua, passa a ser uma coisa rotineira, até estranha quando não há. (Enfermeira)

$\mathrm{N}$ ão sei, às vezes, tu te irritas um pouco, porque, eles brigam, mas, normalmente, até paciente custodiado eu não consigo ver como bandido, [...]. Estão acorrentados [...] mas a gente trata como se fosse um paciente qualquer. (Auxiliar de Enfermagem)

A violência parece estar integrada e faz parte do dia-a-dia do hospital, é a banalização. A contradição ou a ambivalência fica evidente nas fal as e atesta que as trabal hadoras buscam formas para esse enfrentamento. Percebe-se, na fala, acima, essa ambivalência, mas a realidade descrita por essa trabal hadora não é vivenciada por todo o grupo. 0 modo de cuidar assume diferentes formas. Algumas trabal hadoras expressam suas dificuldades e os sentimentos que mais interferem no cotidiano do cuidado.

A cho que agora estou mais acostumada, mas no início fiquei mais chocada com eles. [...] eu tinha mais medo de chegar perto ou que ele se soltasse da corrente e viesse pegar a gente, tentar fugir, mas agora não, estou mais acostumada. (Auxiliar de Enfermagem)

É inquestionável que as trabalhadoras de enfermagem precisam ter preparo e apoio para enfrentar e lidar com situações de conflito no cuidado a esse tipo de paciente, em especial ao que "é considerado marginal". As condutas desses pacientes são parecidas e al gumas trabalhadoras "sabem o que fazer" e "como abordá-los".

$N$ ão tenho dificuldade. [...] alguns colegas têm, não sei se são mais sensíveis com a maneira dos pacientes se portarem. Eu brinco com os meus pacientes, alguns dou uma pesquisada vejo se dá para contar piadas ou não [...]. . (Auxiliar de Enfermagem)

É importante frisar que a fala acima é de um trabal hador que atua há três décadas no HPS e considera-se que o gênero influencia nas formas de lidar com e sobre as conseqüências da violência. As situações constrangedoras e 0 comportamento agressivo dos pacientes são infligidos principalmente às mulheres.

Cada unidade de internação tem uma rotina estabelecida para o primeiro atendimento ao paciente e é direcionada pelo tipo de trauma. Entretanto, a primeira abordagem ao paciente é realizada da manei ra que cada trabaIhadora de enfermagem considera ser a mais adequada. $\mathrm{Na}$ instituição, segundo informam, não há espaços de discussão sobre esse cuidado, considerado "rotina" em um hospital como 
esse. As falas das auxiliares evidenciam que existe interesse em interagir com o paciente, possibilitando-Ihe que se expresse sobre 0 agravo e sobre o trauma. A escuta é uma demonstração de interesse pela pessoa que está sendo recebida no serviço.

Tu percebes quando a pessoa quer falar, logo ela conta tudo ou então se retrai e nesses casos sei que não é para perguntar. (Auxiliar de Enfermagem)

0 profissional sabe quando 0 assunto não deve ser abordado, quando "a conversa não de ve continuar". N esse momento, a relação de interação é interrompida. Assim, cada uma das trabalhadoras irá lidar com o paciente da maneira que considera mais apropriada.

$\mathrm{N}$ as falas sobre o primeiro atendimento ao paciente percebe-se que esse fazer ou cuidar difere entre as diferentes categorias das trabalhadoras de enfermagem. $\mathrm{N}$ os depoimentos aci$\mathrm{ma}$, as auxiliares direcionam sua abordagem para o conhecimento e informações sobre o indivíduo e o modo com que irão relacionar-se com ele. Já, as enfermeiras direcionam sua abordagem ao planejamento do cuidado.

Eu me interesso em saber como e por que aconteceu enquanto isso interferir no cuidado que ten ho que desenvolver. [...] colho a história da agressão, algum detal he, alguma coisa que não foi revelada eque percebi que ali havia algo diferente daquilo que foi contado, mas com interesse no tratamento e não como uma mera curiosidade. (Enfermeira)

Essas fal as das enfermeiras, porém, são condutas isoladas, porque não existe uma proposição institucional de que esse tipo de agravo influencia no planejamento do cuidado. Em virtude dessa "omissão institucional" al gumas trabalhadoras consideram que as circunstâncias e os motivos que envolvem a hospitalização decorrente de violência não devem ser considerados no primeiro momento da internação do paciente.

Acredito que eu não vá muito além da coisa bem formal, colhendo informações mínimas, nesse processo que trabalhamos aqui na instituição. [...] esse fato de ter feito determinado ato, de estar acompanhado pelos policiais, isso gera algum sentimento. (Enfermeiro)

Dessa forma, o primeiro atendimento na unidade de internação e o planejamento do cuidado estão voltados ao trauma que cada paciente sofreu, exceto quando envolve violência doméstica, principalmente quanto aos maustratos à criança.

Considera-se "omissão institucional" o fato de não ter, no hospital, um protocolo estabele- cendo o envolvimento da Instituição e dos profissionais de saúde, no atendimento ao usuário, considerando a violência como um problema de saúde pública. Não existe capacitação dos profissionais para a detecção desse agravo, nem a possibilidade de encaminhar o usuário a serviços de referência visando a que o mesmo tenha a oportunidade de sair do ciclo da violência.

A interação do paciente com a equipe vai se estabelecendo desde o primeiro momento da internação, mas poderá ter desfechos desagradáveis, quando se perde o controle.

No momento da acolhida, ele sempre é uma vítima, é recebido como uma pessoa que está sofrendo e foi agredida, mas com o passar das horas, da avaliação e com a leitura que as pessoas fazem disso é que vai mudando. Às vezes temos situações em que isso muda completamente, partindo de uma excelência para um grau muito ruim de atendimento à saúde. (Enfermeira)

Esse "grau ruim de atendimento à saúde", gerado pelo conflito envolvendo pacientes cuja internação é decorrente de violência, causa frustração para al gumas trabalhadoras. Algumas entendem que o despreparo dos profissionais de saúde, em geral, para enfrentar um serviço público de atendimento ao trauma, dificulta o trabalho não só da enfermagem, mas da instituição como um todo.

Certamente, há tanto preconceito [...]. Para os trabalhadores dos setores, os pacientes que chegam nessas condições, todos são marginais e têm que ter tratamento para marginal, o que eu discordo. [...] mesmo sendo um bandido ele deve receber atendimento digno, pois estamos aqui para isso, depois ele vai acertar suas contas com a justiça, mas as pessoas não levam isso em conta [...]. (Enfermeiro)

0 reconhecimento de que o preconceito exclui do indivíduo os seus direitos de cidadão também é expresso por uma enfermeira, que reflete sobre a vulnerabilidade de determinados indivíduos à exclusão, inclusive do direito ao atendimento igualitário à saúde, preconizado pelo SUS.

$\mathrm{N}$ o que se refere ao direito de cidadania dos pacientes envolvidos com situações de violência, não há o reconhecimento pela equipe de enfermagem e médica [...]. Os pacientes de uma forma geral são punidos duplamente pela vulnerabilidade em que se encontram e pela situação de injúria que sofrem [...]. O s profissionais de saúde querem justiça com os "culpados". M as não refletem sobre as ações de quem detém o poder, e nem percebem que os ditos "culpados" são sempre os mesmos os e que possuem os três pês: pretos, po- 
bres e psicóticos. É necessário assumir as responsabilidades de agir, para clarear a visão embaçada que impede de tratar com as diferenças. (Enfermeira)

Esse é o primeiro momento em que uma trabal hadora relaciona raça/cor com os pacientes que internam em decorrência da violência. Considera-se a necessidade desse e de outros olhares, para que as trabalhadoras possam entender as tramas que envolvem as relações sociais geradoras e sustentadas na exclusão e marginalização de alguns segmentos da sociedade. Vários autores (Cruz-N etto \& M inayo, 1994; Sant'Anna, 2000; Sant'Anna e Lopes, 2002) ressaltam essa diversidade de olhares e a urgência da inclusão dessas temáticas na qualificação dos profissionais e trabalhadores de saúde pública.

A categoria "Estratégias de enfrentamento no cuidado às vítimas e agressores" revela que os pacientes já chegam "marcados", os profissionais já sabem que farão todos os cuidados, mas de outra forma:

Eu acho que a equipe, que nós temos outro ol har para esse paciente que é vítima de arma de fogo, então já tens um preconceito [...]. (Enfermeiro)

Em primeiro lugar tu cortas qualquer tipo de intimidade: "não sou tua tia, meu nome étal", estou cuidando de ti [...]. (Auxiliar de Enfermagem)

Evitar qualquer tipo de intimidade pode ser um modo para estabelecer a distância que protegerá a trabalhadora do envolvimento com as questões relacionadas à violência, é como se fosse possível fazer um descolamento do contexto e só ficar envolvida com a prática técnica, para poder suportar o conflito e o sofrimento causados no enfrentamento dessas situações. Outra alternativa é "procurar não saber" o motivo da internação.

Eu como não sei, o que eu faço procuro não saber da história, para não misturar a razão com a emoção, então, foi assim que eu aprendi, mas não é uma regra básica, não sei seé o certo, esse é o jeito que eu lido com esse paciente [...]. (Auxiliar de Enfermagem)

Os autores Bouvier (1989); Dejours (1988); Pitta (1991); Tittoni (1994); Lopes (1995) referem-se a estratégias para suportar al gumas situações do cotidiano do trabalho. Até o momento, pode-se afirmar, que o convívio cotidiano com vítimas e agressores gera conflitos e dificuldades para as trabal hadoras da enfermagem, e conviver com personagens das manche- tes policiais, para muitas delas, precisa ser enfrentado com auxílio de "algumas estratégias". As falas das trabalhadoras de enfermagem revelam os "sistemas sociais de defesa" referidos por Pitta (1991), os quais, nesta pesquisa, auxiliam a entender as "estratégias" que utilizam no enfrentamento dos conflitos cotidianos no cuidado.

A primeira defesa corresponde à fragmentação da relação técnico-paciente, em que a trabal hadora busca o parcelamento das tarefas, no intuito de reduzir os tempos de contato técnico com o paciente, pois quanto menos íntimo for o relacionamento menor o risco de mobilizar sentimentos de angústia ou revolta.

Não tenho nenhuma dificuldade, gosto de cuidar desse paciente. $\mathrm{N}$ ão sei se pelo meu jeito de ser, tipo de personalidade, tanto que às vezes tenho colegas que têm dificuldade e eu digo que posso cuidar. Eles falam horrores, te botam debaixo do tapete, então [...] tens que fazer uma cortina de isolamento e fazer o teu trabalho [...]. (Auxiliar de Enfermagem)

No momento em que a trabalhadora "cuida" do paciente, escalado para ser cuidado pela outra, o trabalho é fragmentado. Em geral, é feita uma troca de favores, ou seja, o cuidado aos pacientes escalados será realizado por procedimentos e não de modo integral, pois cada uma fará "uma parte". Essa troca, além de propiciar que cada uma faça os cuidados de sua preferência, "alivia" a "carga psíquica do trabaIho", por diminuir as situações de enfrentamento. A segunda defesa é a despersonalização e negação da importância do indivíduo, na qual todos os pacientes são iguais e devem ser cuidados da mesma forma:

$N$ ão consegue interferir no meu modo de cuidar, eu consigo bloquear, eu consigo trabalhar legal na minha cabeça. Eu procuro não pensar sobre esse paciente, não ver o porquê. [...] não pensar no problema dele, para não interferir no meu lado profissional. Procuro não ver, se é vítima, se não é. [...] não ligar a história do paciente ao meu trabalho, sempre procuro pensar que independente do que for, ele é um paciente. (Auxiliar de Enfermagem)

Somos agentes da saúde, nós somos cuidadores e quando se trata de violência nós estamos aqui meio que "santos", tu atendes 0 agressor ea vítima e na hora tu não tens o que fazer, vais atender igual tanto a vitima como 0 agressor. (Enfermeira)

A fala, "independente do que for, ele é um paciente", significa que para a enfermagem "to- 
dos" os pacientes são iguais. Pitta (1991) salienta que a estrutura hospitalar contribui para a despersonificação do indivíduo, e cita, por exemplo, as roupas iguais vestidas nos pacientes. No HPS, esse processo inicia no momento da internação, quando o indivíduo veste a "camisola" do hospital. Na ausência de familiares, a enfermeira aciona um funcionário do setor de pertences, para ir até a enfermaria e recolher a roupa e os objetos de valor (dinheiro, documentos, jóias, entre outros) do paciente, só retirados desse setor por algum familiar autorizado.

A terceira defesa refere-se ao distanciamento e negação de sentimentos. Para tanto, o profissional precisa refrear 0 envolvimento com 0 paciente e controlar os seus sentimentos, estratégia mais utilizada pelas trabalhadoras que compõem este estudo.

[...] eu procuro não conversar muito, não posso ser eu, tenho que ser mais séria, para cuidar deles a gente tem que ser diferente do que seria, para cuidar de um trabalhador. (Auxiliar de Enfermagem)

[...] se tem trabalhado mais com esse paciente já com perfil de presidiário, de ex-presidiário, acho que é como esfriar os corpos, esfriar as coisas, tu tiras um pouco da coisa de humano para poder conseguir estar trabalhando, a gente enfrenta alguma coisa [...] esse sentimento de que ao mesmo tempo estás tratando essas pessoas eao sair daqui corres o risco de ser vítima dessa violência [...]. (Enfermeiro)

A enfermagem, atualmente, é uma profissão na qual as categorias que a compõem buscam realizar suas atividades baseadas em princípios do cuidado humanizado, em especial, no ambiente hospitalar. Portanto, quando o enfermeiro refere que é preciso retirar um pouco da coisa de humano, para poder seguir trabalhando, está racionalizando seu pensamento, mas exprime o esforço para esse enfrentamento no cuidado ao paciente hospital izado em decorrência de agressão.

Skaba (1997) entende que os serviços de emergência são locais de extrema vulnerabilidade ao sofrimento no trabalho. Entretanto, alguns profissionais negam esse processo. A afirmação da autora vem ao encontro do que se pensa em relação à utilização da estratégia de negação dos sentimentos, como alternativa para suportar o impacto da violência em um serviço público de emergência em trauma.

Angulo-Tuesta (1997) salienta que os indivíduos sobreviventes da violência representam uma demanda significativa para os serviços de emergências e, referindo-se à violência doméstica, aponta para a importância dos serviços de saúde desenvolverem ações não somente voltadas ao dano físico, mas intervenções mais integrais, reconhecendo que a violência de gênero precisa de uma abordagem mais ampla, ressaltando que qualquer proposta nesse sentido deve considerar o envolvimento dos profissionais de saúde.

\section{Considerações finais}

O sistema de saúde brasilei ro chega a um limite em que não é mais possível conciliar 0 atendimento público em saúde com a alienação de muitos profissionais, quanto ao entendimento das relações conflituosas originadas no cotidiano de violência e exclusão social de al guns segmentos da sociedade. É necessário promover a construção da consciência social do trabal hador de saúde, diz Skaba (1997).

As trabal hadoras lidam com seus conflitos individual e coletivamente, ou seja, não há uma preocupação do hospital garantir um suporte psicológico para que as mesmas possam enfrentar as dificuldades do dia-a-dia.

As estratégias para suportar o "sofrimento" são criadas entre o grupo, por acordos, como, 0 auxílio mútuo no cuidado aos pacientes, como, por exemplo, assumir o paciente agressivo que está na escal a de outra colega.

0 desafio de conhecer como os profissionais de enfermagem planejam, confrontam, pensam e executam o cuidado ao paciente hospitalizado vítima de violência, oportunizou uma reflexão das próprias trabalhadoras sobre o tema, pois por um momento pararam para olhar e pensar sobre esse cotidiano de trabalho que até então só era executado. Ficou evidente que cada uma lida com esse cuidado da forma que acredita ser a mais adequada e utiliza as estratégias que conhece para suportar e enfrentar essa realidade. As principais dificuldades destas trabalhadoras são, principalmente, o despreparo para lidar com esse tipo de paciente; e a falta de comprometimento institucional tanto em relação ao apoio psicológico às trabalhadoras, quanto à capacitação, das mesmas, voltada ao atendimento e cuidado dos pacientes.

Considera-se que a violência é um problema que atinge todo o país e é resultante principalmente das desigual dades sociais que assolam não só o Brasil, mas toda a América Lati- 
na. N ão se tem a pretensão de acreditar que os serviços públicos de saúde tenham toda a responsabilidade de arcar com o combate a violência, entretanto a este setor cabe o envolvimento institucional com a capacitação dos profissionais de saúde para esse enfrentamento, respaldados na compreensão das relações sociais.
A ponta-se também que a compreensão das relações sociais é adquirida através da construção de uma consciência política voltada para o coletivo, e enfatiza-se que, principalmente, os serviços públicos de saúde necessitam se autoavaliar e propiciar e criação de espaços de discussão sobre o tema.

\section{Colaboradores}

S Leal escreveu este artigo a partir do estudo realizado em sua dissertação de mestrado ("Violência como objeto da assistência em um hospital de trauma: 0 olhar da enfermagem"). Defendida na Escola de Enfermagem da UFRGS, no Núcleo de Estudos Interdisciplinares de Gênero Saúde eTrabal ho (GENST) (maio 2003). M Lopes realizou o trabalho de orientação da pesquisa e revisão do texto. 


\section{Referências bibliográficas}

A bramovay M et al. 2002. Juventude, violência e vulnerabilidade social na América Latina: desafios para políticas públicas. Unesco, BID, Brasília.

Angulo-Tuesta MJ 1997. Gênero e violência no âmbito doméstico: a perspectiva dos profissionais de saúde. Dissertação de mestrado. Escola Nacional de Saúde Pública, Fundação Oswaldo Cruz, Rio de Janeiro.

Barros M BA 1984. Consideração sobre a mortalidade no Brasil em 1980. Revista de Saúde Pública 18:122-137.

Bouvier P 1989. Le travail au quotidien: une démarche socio-anthropologique. P.U.F., Paris.

Brasil 1996. M inistério da Saúde. Conselho Nacional de Saúde. Resolução 196/96 sobre pesquisas envolvendo seres humanos. Diário Oficial da U nião 16/10/96: 21.082-21.085.

Briceño-León R 2002. La nueva violencia urbana de América Latina, pp. 13-26. In Briceño-León (org.). Violencia, sociedad y justicia en América Latina. Clasco, BuenosAires.

Chesnais JC 1999. A violência no Brasil. Causas e recomendações políticas para a sua prevenção. Ciência e Saúde Coletiva 4(1):53-69.

Cruz-N etto O \& M inayo M CS 1994. Extermínio: violentação e banalização da vida. Cadernos de Saúde Pública 10(1):199-212.

Dagord ALL 2002. Violência contra a mulher ainda é um desafio, pp. 23-28. In M R Nunes (org.). 0 direito humano das mulheres e das meninas: enfoques feministas. Assembléia Legislativa do RS, Porto Alegre.

Dejours, C 1988. A loucura do trabalho. Cortez, São Paulo.

Deslandes SF 1999. 0 atendimento às vítimas de violência na emergência: "prevenção numa hora dessas"? Ciência Saúde Coletiva 4(1):81-94.

Deslandes SF 2002. Frágeis deuses: profissionais da emergência entre os danos da violência ea recriação da vida. Fiocruz, Rio de Janeiro.

IBGE 2002. Censo demográfico 2000: primeiros resultados da amostra. IBGE, Rio de Janeiro.

Leal 2003. Violência como objeto da assistência em um hospital de trauma: o "olhar" da enfermagem. Dissertação de mestrado. Escola de Enfermagem da U niversidade Federal do Rio grande do Sul, Porto Alegre.

Lopes M JM 1995. Quando a voz e a palavra são atos terapêuticos: a interação individual e coletiva nas palavras cotidianas do trabalho de enfermagem, pp. 153188. In VR Waldow, M JM Lopes \& DE M eyer (orgs.). $M$ aneiras de cuidar e maneiras de ensinar: a enfermagem entre a escola ea prática profissional. Artes M édicas, Porto Alegre.

Lopes M JM \& Sant'Anna AR \& Aerts DRG Castro 2002. A mortalidade por homicídios em adolescentes em Porto Alegre de 1998 a 2000. 17 f. Relatório de Pesquisa Fundação de Amparo a Pesquisa do Rio Grande do Sul, Porto Alegre. GENST/ EEN F/UFRGS. (Não publicado).
M inayo M CS 2000. 0 desafio do conhecimento: pesquisa qualitativa em saúde. (7ạ ed.). Hucitec-Abrasco, São Paulo-Rio de Janeiro.

M inayo M CS et al. 1999. Fala galera: juventude violência e cidadania no Rio de Janeiro. Garamond, Rio de Janeiro.

M inayo M CS \& Souza ER 1993. Violência para todos. Cadernos de Saúde Pública 9(1):65-78.

M inayo M CS \& Souza ER 1999. É possível prevenir a violência? Reflexões a partir do campo da saúde pública. Ciência Saúde Coletiva 4(1):7-32.

N egrão T 2002. A rede de defesa dos direitos humanos das mulheres, pp. 101-106. In M R Nunes (org.). 0 direito humano das mulheres e das meninas: enfoques feministas. Assembléia Legislativa do RS, Porto Alegre.

N unes M R 2002. $O$ direito humano das mulheres e das meninas: enfoques feministas, pp. 9-12. In M R Nunes (org.). 0 direito humano das mulheres e das meninas: enfoques feministas. Assembléia Legislativa do RS, Porto Alegre.

Oliveira CSO 2001. Sobrevivendo no inferno: a violência juvenil na contemporaneidade. Sulina, Porto Alegre

Oliveira HA 2002. Violência doméstica contra a criança e 0 adolescente, pp. 137-140. In MF Westphal MF (org.). Violência e criança. Editora da U niversidade de São Paulo, São Paulo.

Pitta A 1991. H ospital: dor e morte como ofício. Hucitec, São Paulo.

Sant'Anna AR 2000. Vulnerabilidade ao homicídio: sóciohistória das mortes violentas dos adolescentes na cidade de Porto A legre em 1997. Dissertação de mestrado. Escola de Enfermagem da Universidade Federal do Rio grande do Sul, Porto Alegre.

Sant'Anna AR \& Lopes MJM 2002. Homicídios entre adolescentes na cidade de Porto Alegre, Rio Grande do Sul, Brasil: vulnerabilidade e culturas de gênero. Cadernos de Saúde Pública 18(6):1.509-1.517.

Skaba M M VF 1997. 0 vício da adrenalina: etnografia da violência num hospital de emergência. Dissertação de mestrado. Escola Nacional de Saúde Pública, Fiocruz, Rio deJaneiro.

Souza ER \& M inayo M CS 1999. 0 impacto da violência social na saúde pública do Brasil: década 80, pp. 87116. In M CS M inayo (org.). Os muitos brasis: saúdee população na década de 80 . Hucitec-Abrasco, São Paulo-Rio de Janeiro.

Tittoni J 1994. Subjetividadee trabalho. Ortiz, Porto Alegre. Zaluar A 1986. Crime e trabalho no cotidiano popular. Ciência H oje 5(supl.) :21-24.

Artigo apresentado em 23/01/2004

Aprovado em 15/04/2004

Versão final apresentada em 7/12/2004 